\title{
Frequency and Determinants of Vitamin D Deficiency Among Premenopausal and Postmenopausal Women: A Multicenter Study in Karachi, Pakistan
}

Uzma Shamsi ( $\nabla$ uzma.shamsi@adelaide.edu.au )

University of Adelaide

Iqbal Azam

Aga Khan University

Azra Shamsi

Combined Military Hospital

Dua Shamsi

University of California, Berkeley

David Callen

University of Adelaide

\section{Research Article}

Keywords: vitamin D, premenopausal, deficiency, health

Posted Date: February 3rd, 2021

DOI: https://doi.org/10.21203/rs.3.rs-151558/v1

License: (a) (i) This work is licensed under a Creative Commons Attribution 4.0 International License.

Read Full License 


\section{Abstract}

Background: Vitamin D deficiency is becoming a serious public health problem, even in sun-drenched cities like Karachi, Pakistan. We investigated the prevalence of vitamin D deficiency VDD and its association with sociodemographic characteristics, anthropometric measures, and lifestyle factors among Pakistani women $(n=784)$.

Methods: Face-to-face interviews were conducted to collect information from premenopausal and menopausal women and serum 25(OH)D was measured after the interview.

Results: The mean age of the women was 46.2 years, and the mean 25 -hydroxyvitamin $D(+/-S D)$ levels were $22.9 \mathrm{ng} / \mathrm{ml}(+/-20.3)$. A total of $57 \%$ of women were vitamin $D$ deficient with higher vitamin $D$ deficiency found among premenopausal (64.7\%) women compared to menopausal women (49\%). Factors associated with vitamin D deficiency were lower socioeconomic status (OR 2.00; $95 \% \mathrm{Cl} 1.15-$ 3.48), younger age with highest vitamin $\mathrm{D}$ deficiency in $<35$ years of age (OR $3.11 ; 95 \% \mathrm{Cl} 1.76-5.51)$, and winter season (OR 1.51, 95\% $\mathrm{Cl} 1.07-2.15)$ after adjusting for multiple confounders. The use of vitamin D supplement use (OR 0.59, 95\% $\mathrm{Cl} 0.38-0.92)$ and vigorous exercise (OR 0.20, $95 \% \mathrm{Cl} 0.05-0.80)$ was protective against vitamin $\mathrm{D}$ deficiency.

Conclusions: The study shows a high prevalence of vitamin D deficiency, with detrimental health effects among younger women belonging to lower socioeconomic status during the winter season. The use of vitamin D supplements and vigorous exercise were protective measures. Public health campaigns are needed for education and awareness about vitamin $D$ deficiency to improve vitamin $D$ status for younger women living in poor environments.

\section{Background}

Vitamin D deficiency VDD ( $<20 \mathrm{ng} / \mathrm{ml})$ is becoming common and increasing in majority of population worldwide. There is also a lot of research interest in studies assessing the role of VDD in many diseases including the recent pandemic of Covid 19(1,2). VDD is an important public health problem in Pakistan too. According to a study in Hyderabad, both VDD and vitamin D insufficiency was $78.3 \%$ among 1244 healthy individuals (3). In another study, at Ayub Teaching Hospital Abbottabad, high VDD was reported among 202 patients (63.4\%) with complaints of generalized body aches (4). A study conducted among healthy women of child-bearing age in Lahore reported that VDD was $73 \%$. Factors associated with VDD were lesser sun exposure, illiteracy, winter season during sampling and no usage of multivitamins were the risk factors. A cross-sectional population survey among 300 adult population of Karachi showed median level of serum vitamin $D$ as $18.8 \mathrm{ng} / \mathrm{dL}$ with high prevalence of VDD (5). VDD was reported as $90.1 \%$ among 305 premenopausal females in a cross-sectional study in Karachi, Pakistan. Factors associated with VDD were age, city of residence in downtown and suburbs, and type of housing (6). In a recent study among 221 medical students of a medical school, VDD was found in $89.14 \%$ and factors associated with VDD were limited sun exposure and attire consisting of full length of sleeves outside (7). 
There is a lot of variation in the vitamin D status of women living in Karachi in different studies, most of which consisted of smaller sample sizes and only few factors causing VDD were assessed. Therefore, the objective of the study was to investigate all the factors associated with VDD among women of both premenopausal and menopausal status in Karachi Pakistan.

\section{Methods}

\section{Study Population}

We extracted data of 784 women, who were in the control group and had complete information on potential predictors of VDD and serum 25(OH)D concentrations, from the case control study (the details of which are mentioned in a recently published article) (8). All the women were interviewed attending inand out-patient services for general medical, and surgical departments. Exclusion criteria were history of any cancer, parathyroid, renal or liver disease, chronic malabsorption syndromes or any known or suspected drug that may alter vitamin D metabolism.

Face to face interviews were conducted and information was collected about sociodemographic factors, clinical and reproductive history, sun exposure, use of vitamin D supplementation, and anthropometric measurement. Age was categorized into $<35,35-45,46-54,>55$ years. Education was categorized as < $8,8-12$, or $>12$ years of education. Socio-economic (SES) factors included were multiple variables like crowding index (the number of household members divided by number of rooms) and was further categorized as $<1,1-2,>2$. A composite variable was calculated for socioeconomic status by factor analysis of important variables like education, place and type of residence, crowding index, home ownership, number of rooms, total household members, total household monthly income. Finally, SES was categorized into upper, middle and lower status (8).

\section{Sun exposure measurement questionnaire}

The validated Long-Term Sun Exposure Measurement Questionnaire (LT SEM-Q) was used to assess sun exposure among women (9). This questionnaire assessed sunlight exposure, duration of sun exposure, skin tone, use of sunscreens and sun avoidance behaviour. The time spent outdoors between 10 am and $4 \mathrm{pm}$ was asked to calculate approximate amount of time in minutes per week women were exposed to UVB radiations. Details of weights given to sun exposure variables are in the supplementary table $A$. The final scoring algorithm of sun exposure score in summers and winters was created by multiplying the time (minutes) spent in the sun by the proportions of the different variables. The skin tone of the women was assessed using a shade card (10 skin tones (1-10)) by matching shade of the skin on forehead with the shade on the card, according to LT SEM-Q.

\section{Vitamin D supplements}

Use of vitamin intake was asked in detail as types of intake, duration and form of intake as injectable, oral drops or capsules apart from intake as yes vs. no. 


\section{Measurement of serum 25(OH)D concentrations}

Venous blood samples $(2.5 \mathrm{ml})$ were taken from all participants and collected in yellow topped gel tubes at the end of the interview. Serum 25(OH)D concentrations were measured by a kit from DiaMetra S.r.l. Headquarter: Via Garibaldi, 18-20090 SEGRATE (MI) Italy, using solid phase enzyme-linked immunoassay (ELISA). The cut-off used to define VDD was according to the Parathyroid Hormone (PTH) levels (10). Vitamin D deficiency was defined as a serum 25-hydroxyvitamin D concentrations $\leq 20 \mathrm{ng} / \mathrm{ml}$. Season of blood collection (winter/ spring vs. summer /fall) was also recorded.

Other variables included fish consumption (asked as no intake vs. least once per month vs. more) and $\mathrm{BMI}$ (calculated as weight in kilograms divided by the square of height in meters. Women were categorized for their BMI according to the World Health Organization (WHO) cut off for BMI (11): a normal weight (18.5-24.9 kg/m2), being overweight $(25.0-29.9 \mathrm{~kg} / \mathrm{m} 2)$ or obese $(>30 \mathrm{~kg} / \mathrm{m} 2)$.

\section{Statistical analysis}

Mean and standard deviations are reported for continuous variables and frequencies and percentages for categorical variables to illustrate the differences in vitamin $D$ concentrations between premenopausal and menopausal women. The crude and adjusted ORs and $95 \% \mathrm{Cl}$ s were calculated for VDD (vitamin D level lower than $20 \mathrm{ng} / \mathrm{ml}$ versus a non deficient vitamin D status) through logistic regressions while entering the following variables as predictors in the model: age, education level, parity, SES, season, BMI, use of vitamin D supplements, fish consumption, exposure to sunlight, sun avoidance behaviors.

Statistical analysis of the data was carried out using the SPSS package for Windows 22.0 (SPSS, IBM, Armonk, NY, USA).

\section{Results}

Mean 25(OH)D level was $22.9 \mathrm{ng} / \mathrm{ml}$ (SD 20.3) and median level was $16.7 \mathrm{ng} / \mathrm{ml}$. There was high prevalence of VDD among both pre and postmenopausal women. Individual 25(OH)D concentrations ranged from $0.3 \mathrm{ng} / \mathrm{ml}$ to $165.5 \mathrm{ng} / \mathrm{ml}$. The median 25(OH)D level was lower among premenopausal women $(13.9 \mathrm{ng} / \mathrm{ml})$ compared to menopausal women $(20.4 \mathrm{ng} / \mathrm{ml})$.

Women were further categorized into four different concentrations of $25(\mathrm{OH}) \mathrm{D}$, defined as severely deficient (<12 ng/ml), deficient (12-19 ng/ml), insufficient $(20-30 \mathrm{ng} / \mathrm{ml})$ and sufficient $(>30 \mathrm{ng} / \mathrm{ml})$ (Table 1). Both severe vitamin $D$ deficiency and deficiency was significantly more frequent in premenopausal women compared to menopausal women. 
Table 1

Number and percentage of women for different serum 25(OH)D concentrations

\begin{tabular}{|c|c|c|c|c|c|c|c|c|}
\hline \multirow[t]{3}{*}{$\begin{array}{l}\text { Serum 25(OH)D } \\
(\mathrm{ng} / \mathrm{ml})\end{array}$} & & \multicolumn{2}{|c|}{$\begin{array}{l}\text { Premenopausal } \\
\text { women }\end{array}$} & \multicolumn{2}{|c|}{$\begin{array}{l}\text { Menopausal } \\
\text { women }\end{array}$} & \multicolumn{2}{|c|}{ All women } & \multirow[t]{2}{*}{$\mathrm{p}_{\text {value }}$} \\
\hline & & $\mathbf{n}$ & $\%$ & $\mathrm{n}$ & $\%$ & $\mathbf{n}$ & $\%$ & \\
\hline & & & & & & & & $<.001$ \\
\hline Severely deficient & $<12$ & 124 & $39.9 \%$ & 78 & $26.2 \%$ & 202 & $33.2 \%$ & \\
\hline Deficient & $\begin{array}{l}12- \\
19\end{array}$ & 77 & $24.8 \%$ & 68 & $22.8 \%$ & 145 & $23.8 \%$ & \\
\hline Insufficient & $\begin{array}{l}20- \\
30\end{array}$ & 52 & $16.7 \%$ & 61 & $20.5 \%$ & 113 & $18.6 \%$ & \\
\hline Sufficient & $>30$ & 58 & $18.6 \%$ & 91 & $30.5 \%$ & 149 & $24.5 \%$ & \\
\hline
\end{tabular}

Table 2 shows that VDD was higher in younger compared to older women. The majority of the women had skin tone of 5 and 6 categorized as wheatish tone, however, skin tone was not associated with serum $25(\mathrm{OH}) \mathrm{D}$ levels. As it was a hospital-based study, it was observed that a higher percentage $(63 \%)$ of women took vitamin D supplements and fish intake was less frequent and nearly $40 \%$ women ate no fish at all. 
Table 2

Socio-demographic and clinical characteristics of both premenopausal and menopausal women $(n=$ 784) with and without vitamin D deficiency in Karachi, Pakistan

$\begin{array}{ccccc}\text { Categories } & \text { vitamin } \mathrm{D}>20 & \text { Vitamin D deficiency } \leq 20 & \text { OR }(95 \% \mathrm{Cl}) \\ \mathrm{n} & \% & \mathrm{n} & \%\end{array}$

\section{Age groups}

\begin{tabular}{llllll}
$<35$ & 29 & 10.9 & 65 & 18.7 & $3.46(2.00,5.97)$ \\
\hline $35-45$ & 77 & 28.9 & 144 & 41.4 & $2.88(1.88,4.43)$ \\
\hline $46-54$ & 69 & 25.9 & 80 & 23.0 & $1.79(1.13,2.83)$ \\
\hline $55 \&$ above & 91 & 34.2 & 59 & 17.0 & Ref
\end{tabular}

\section{Education}

$<$ grade8

49

$18.4 \quad 68$

19.5

$1.07(0.69,1.65)$

grades 8-12

87

$32.7 \quad 111$

31.9

$0.98(0.68,1.41)$

$>$ grade 12

130

$48.9 \quad 169$

48.6

Ref

\section{Socioeconomic status}

\begin{tabular}{llllll} 
upper & 61 & 22.9 & 52 & 14.9 & $2.62(1.58,4.34)$ \\
\hline middle & 158 & 59.4 & 191 & 54.9 & $1.42(0.92,2.17)$ \\
\hline lower & 47 & 17.7 & 105 & 30.2 & Ref \\
\hline Parity ${ }^{\text {a }}$ & & & & & \\
\hline nullipara & 34 & 12.8 & 59 & 17.0 & $0.82(0.50,1.350$ \\
\hline 43833 & 136 & 51.1 & 152 & 43.7 & $0.64(0.40,1.04)$ \\
\hline$>3$ & 96 & 36.1 & 137 & 39.4 & Ref \\
\hline menopause & & & & & $1.90(1.38,2.63)$ \\
\hline menopause & 152 & 58.0 & 146 & 43.0 & Ref
\end{tabular}

'Parity was restricted to women who ever had a full-term pregnancy (a pregnancy was considered as full-term if it resulted in a live birth or lasted 7 or more months)

${ }^{\mathrm{b}} \mathrm{BMI}$, body mass index; $\mathrm{BMI}$ was categorized according to the WHO classification for Asian as underweight/normal weight (<23 kg/m2), overweight $(23-25 \mathrm{~kg} / \mathrm{m} 2)$ or obese $\left(\_26 \mathrm{~kg} / \mathrm{m} 2\right)$.

Abbreviations: $\mathrm{OR}$, odds ratio $\mathrm{Cl}$, confidence interval

Reference: OR are compared to those women who had VDD 


\begin{tabular}{|c|c|c|c|c|c|}
\hline Categories & \multicolumn{2}{|c|}{ vitamin $D>20$} & \multicolumn{2}{|c|}{ Vitamin $\mathrm{D}$ deficiency $\leq 20$} & OR (95\% Cl) \\
\hline \multicolumn{6}{|c|}{ history of any comorbid } \\
\hline yes & 161 & 60.5 & 168 & 48.3 & $0.61(0.44,0.84)$ \\
\hline no & 105 & 39.5 & 180 & 51.7 & Ref \\
\hline \multicolumn{6}{|l|}{ season vitamin $D$} \\
\hline Winter & 102 & 39.2 & 167 & 48.7 & $1.47(1.06,2.04)$ \\
\hline summer & 158 & 60.8 & 176 & 51.3 & Ref \\
\hline \multicolumn{6}{|l|}{ fish consumption } \\
\hline no intake & 107 & 41.2 & 136 & 40.1 & $1.14(0.56,2.29)$ \\
\hline$<$ than once a month & 136 & 52.3 & 184 & 54.3 & $1.21(0.61,2.42)$ \\
\hline > once /month & 17 & 6.5 & 19 & 5.6 & Ref \\
\hline \multicolumn{6}{|c|}{ Vitamin D supplements intake } \\
\hline Yes & 204 & 76.7 & 172 & 49.4 & $0.30(0.19,0.46)$ \\
\hline No & 62 & 23.3 & 176 & 50.6 & Ref \\
\hline Body mass index ${ }^{b}$ & 28.03 & 5.2 & 27.94 & 5.06 & $1.00(0.97,1.03)$ \\
\hline \multicolumn{6}{|c|}{$\begin{array}{l}\text { cParity was restricted to women who ever had a full-term pregnancy (a pregnancy was considered as } \\
\text { full-term if it resulted in a live birth or lasted } 7 \text { or more months) }\end{array}$} \\
\hline \multicolumn{6}{|c|}{$\begin{array}{l}\text { bBMI, body mass index; BMI was categorized according to the WHO classification for Asian as } \\
\text { underweight/normal weight }(<23 \mathrm{~kg} / \mathrm{m} 2) \text {, overweight }(23-25 \mathrm{~kg} / \mathrm{m} 2) \text { or obese }\left(\_26 \mathrm{~kg} / \mathrm{m} 2\right) \text {. }\end{array}$} \\
\hline \multicolumn{6}{|c|}{ Abbreviations: OR, odds ratio $\mathrm{Cl}$, confidence interval } \\
\hline \multicolumn{6}{|c|}{ Reference: OR are compared to those women who had VDD } \\
\hline
\end{tabular}

Table 3 shows lifestyle and sun exposure factors related to VDD. 
Table 3

Lifestyle and sun exposure related factors associated with serum 25-hydroxyvitamin in Pakistani women.

\section{Categories}

Vigorous exercise

$<3.5 \mathrm{hrs} / \mathrm{wk}$

$>3.5 \mathrm{hrs} / \mathrm{wk}$

no exercise

Moderate Exercise

$<3.5 \mathrm{hrs} / \mathrm{wk}$

$>3.5 \mathrm{hrs} / \mathrm{wk}$

no exercise

Walk

$<3.5 \mathrm{hrs} / \mathrm{wk}$

$>3.5 \mathrm{hrs} / \mathrm{wk}$

no exercise

Head Covered

Yes

No

Face Covered

Yes

No

Neck Covered

Yes

No

\section{Full Arm Covered}

Yes

No

Abbreviations: $\mathrm{OR}$, odds ratio $\mathrm{Cl}$, confidence interval

Reference: OR are compared to those women who had VDD

\section{vitamin $D \geq \quad$ Vitamin $D$ deficiency < \\ 20}

\begin{tabular}{lllll}
$\mathbf{n}$ & $\%$ & $\mathbf{n}$ & $\%$ & OR $(95 \%$ Cl $)$ \\
\hline 17 & 6.4 & 7 & 2.0 & $0.82(0.29,2.28)$ \\
\hline 6 & 2.3 & 10 & 2.9 & $0.25(0.07,0.95)$ \\
\hline 243 & 91.4 & 331 & 95.1 &
\end{tabular}

Ref

16.7

$0.59(0.40,0.87)$

28.2

$1.00(0.58,1.72)$

$55.2 \quad$ Ref

180

$67.7 \quad 192$

$29.3 \quad 88$

25.3

$1.59(1.00,2.53)$

$\begin{array}{lll}46 & 17.3 \quad 44\end{array}$

12.6

$1.18(0.71,1.97)$

$\begin{array}{lll}142 & 53.4 & 216\end{array}$

62.1

Ref

$\begin{array}{lllll}171 & 64.3 & 271 & 78.1 & 1.98(1.39,2.83) \\ 95 & 35.7 & 76 & 21.9 & \text { Ref }\end{array}$

39

$14.7 \quad 83$

23.9

$1.83(1.20,2.79)$

$\begin{array}{lll}227 & 85.3 \quad 264\end{array}$

76.1

Ref

129

$48.5 \quad 208$

59.9

$1.59(1.15,2.19)$

$\begin{array}{lll}137 & 51.5 & 139\end{array}$

40.1

Ref

166

$62.4 \quad 255$

73.5

$1.67(1.18,2.36)$

100

$37.6 \quad 92$

26.5

Ref 


\begin{tabular}{|c|c|c|c|c|c|}
\hline \multirow{2}{*}{$\begin{array}{l}\text { Categories } \\
\text { Half Arm Covered }\end{array}$} & \multicolumn{2}{|c|}{$\begin{array}{l}\text { vitamin } D \geq \\
20\end{array}$} & \multicolumn{3}{|c|}{$\begin{array}{l}\text { Vitamin D deficiency < } \\
20\end{array}$} \\
\hline & & & & & \\
\hline Yes & 100 & 37.6 & 88 & 25.4 & $0.56(0.40,0.80)$ \\
\hline No & 166 & 62.4 & 259 & 74.6 & Ref \\
\hline \multicolumn{6}{|l|}{ Attire outside } \\
\hline chadder & 70 & 26.3 & 91 & 26.3 & $1.44(0.95,2.19)$ \\
\hline burqa & 92 & 34.6 & 161 & 46.5 & $1.94(1.33,2.83)$ \\
\hline others & 104 & 39.1 & 94 & 27.2 & Ref \\
\hline \multicolumn{6}{|l|}{ Skin Tone } \\
\hline Dark & 151 & 59.0 & 198 & 59.1 & $1.01(0.72,1.42)$ \\
\hline Wheatish & 93 & 36.3 & 123 & 36.7 & $0.89(0.40,1.98)$ \\
\hline Fair & 12 & 4.7 & 14 & 4.2 & Ref \\
\hline \multicolumn{6}{|l|}{ Season of blood draw } \\
\hline winter & 158 & 60.8 & 176 & 51.3 & $1.47(1.06,2.04)$ \\
\hline summer & 102 & 39.2 & 167 & 48.7 & Ref \\
\hline \multicolumn{6}{|l|}{ Sun avoidance behavior } \\
\hline Yes & 215 & 80.8 & 296 & 85.3 & $1.38(0.90,2.11)$ \\
\hline No & 51 & 19.2 & 51 & 14.7 & Ref \\
\hline $\begin{array}{l}\text { Sunlight exposure score } \\
\text { (summer)* }\end{array}$ & 26.47 & 75.6 & 32.89 & 104.7 & $10.01(0.97,10.06)$ \\
\hline Sunlight exposure score (winter)* & 39.96 & 89.6 & 49.08 & 121.1 & $\begin{array}{l}10.02(9.98 \\
10.05)\end{array}$ \\
\hline \multicolumn{6}{|c|}{ Abbreviations: OR, odds ratio $\mathrm{Cl}$, confidence interval } \\
\hline Reference: OR are compared to tho & women & who ha & VDD & & \\
\hline
\end{tabular}

Table 4 shows the factors associated with vitamin D deficiency were lower socioeconomic status (adjusted OR 2.00; 95\% Cl 1.15-3.48), younger age with highest vitamin D deficiency in < 35 years of age (adjusted OR $3.11 ; 95 \% \mathrm{Cl} 1.76-5.51$ ) and winter season (adjusted OR 1.51, 95\% Cl 1.07-2.15) after adjusting for multiple confounders $(p<0.0001)$. Use of vitamin D supplement use (adjusted OR $0.59,95 \%$ $\mathrm{Cl} 0.38-0.92$ ) and vigorous exercise (adjusted OR $0.20,95 \% \mathrm{Cl} 0.05-0.80$ ) were protective against vitamin D deficiency. 
Table 4

Final table showing adjusted ORs $(95 \% \mathrm{Cl})$ of factors associated with vitamin D deficiency among women in Karachi Pakistan.

\begin{tabular}{|c|c|c|c|}
\hline Variables & Adjusted OR & $95 \% \mathrm{Cl}$ & $\mathrm{p}$ value \\
\hline Age & & & $<0.001$ \\
\hline$<35$ & 3.11 & $1.76,5.51$ & \\
\hline $35-45$ & 2.66 & $1.69,4.19$ & \\
\hline $46-54$ & 1.72 & $1.07,2.77$ & \\
\hline $55 \&$ above & Ref & . & . \\
\hline Socioeconomic Status & & & 0.029 \\
\hline Lower & 2 & $1.15,3.48$ & \\
\hline Middle & 1.23 & $0.77,1.95$ & \\
\hline Upper & Ref & . & \\
\hline Season of blood withdraw & & & 0.05 \\
\hline Winter & 1.51 & $1.07,2.15$ & \\
\hline Summer & Ref & & \\
\hline Vitamin D supplementation use & & & $<0.001$ \\
\hline Yes & 0.59 & $0.38,0.92$ & \\
\hline No & Ref & & \\
\hline Vigorous exercise & & & 0.027 \\
\hline$<3.5 \mathrm{hrs} / \mathrm{wk}$ & 0.63 & $0.21,1.86$ & \\
\hline$>3.5 \mathrm{hrs} / \mathrm{wk}$ & 0.2 & $0.05,0.80$ & \\
\hline No exercise & Ref & & \\
\hline $\begin{array}{l}\text { Adjusted for education, BMI, parit } \\
\text { women who had no vitamin D def } \\
\text { interval }\end{array}$ & $\begin{array}{l}\text { re outside. Ref } \\
\text { iations: OR od }\end{array}$ & $\begin{array}{l}\text { OR are com } \\
95 \mathrm{Cl}=95 \%\end{array}$ & $\begin{array}{l}\text { to those } \\
\text { dence }\end{array}$ \\
\hline
\end{tabular}

\section{Discussion}

In our study, $57 \%$ of women had VDD and only $24.5 \%$ of participants had optimal vitamin D status. Risk of VDD was associated with younger age, lower SES, winter season, while exercise and vitamin D supplement use were protective. A cross-sectional study among 351 patients at the out-patient department of General Medicine of a hospital in Islamabad, reported VDD present in $62.9 \%$ of females 
(mean age $46.03+/-16.18$ years) and the mean vitamin D level was $14.09+/-12.93 \mathrm{ng} / \mathrm{ml}$ (12). In South Florida (U.S.), the mean (+/-SD) of 25(OH)D level was $22.4+/-8.2 \mathrm{ng} / \mathrm{ml}$ in $40 \%$ of women during winter(13). A study conducted in Lahore similarly reported high prevalence of Vitamin D deficiency among healthy women of child-bearing and was also associated with low education and lack of proper sun exposure and multivitamin intake (14).

In a study conducted at an urban hospital in Boston, VDD was associated with winter season, higher body mass index, and physical inactivity(15). In a study in Japan among 4,793 patients with rheumatoid arthritis, the mean (SD) serum 25(OH)D level was $16.9 \mathrm{ng} / \mathrm{mL}$ (6.1), and the prevalence of vitamin D deficiency was $71.8 \%$. Predictors of VDD were female gender, younger age, among other factors that included low serum levels of total protein and total cholesterol, high serum ALP levels, and NSAID (16). VDD was also found high among pregnant women in Belgium (17). Similar to our study finding of association of VDD with younger age, vitamin VDD was found higher in younger women on other studies too (18-22).

Similar to our study, VDD is found to be more common among women during winter/spring compared with summer/autumn (23-25). A study in 3,327 pregnant Japanese women, VDD prevalence was $73.2 \%$ and it was higher in April after the winter season. Sun exposure of >15 mins for 1-2 days / week and usage of dietary vitamin D were protective against VDD (26).

A study conducted in Jinnah Postgraduate Medical Center, Karachi among students showed that VDD was more common in winter (27). A cross-sectional study of 14,302 Chinese participants aged 18-65 years from six major cities in China reported VDD was higher among females, in spring and winter from certain residential regions (28).

A study conducted among pregnant women in Malaysia reported that intake of vitamin D was protective against VDD. There was no association of VDD observed with age, educational, SES, employment, parity, body mass index, sun exposure(29). Another small cross-sectional study in Riyadh, Saudi Arabia, reported VDD among $60.2 \%$ of participants was associated with lack of usage of vitamin D, multi-vitamins (30). Another study in Riyadh, Saudi Arabia reported that absence of vitamin D supplements usage, younger age were factors associated with VDD among females(31). VDD was $75.1 \%$ in a study in France and was associated with no intake of vitamin D (32). A cross-sectional study of 634 healthy volunteers aged 18-50 years reported VDD associated with lack of multivitamin use $(\mathrm{P}<0.001$ for each predictor)(33).

Our study showing lower SES and sedentary lifestyle associated with VDD was also reported by The National Health and Nutrition Examination Survey (NHANES) 2001-2010 (34). A cross-sectional study in Saudi Arabia, reported younger age, less exercise, less Vitamin D intake, as predictors of VDD (35).

Our study results are consistent with findings in few other studies conducted in Switzerland, China and New South Wales showing association of VDD with childbearing age, winter season and no usage of vitamin D supplement (36-38). A large study from the Korean National Health and Nutrition Examination 
Survey (KNHANES) 2008-2009 among 2062 adolescents also showed that VDD was higher in senior high school students and was associated with winter season and parental vitamin D deficiency (39).

Contrary to previous studies across different ethnic backgrounds, this study within Pakistani females showed that skin tone, obesity, etc were not associated with VDD. There was no association observed between VDD and sun exposure questionnaire. In a study in Brazil, the use of sun exposure questionnaire with $250 \mathrm{HD}$ level showed low accuracy and its lack of discrimination between vitamin $D$ sufficient and deficient individuals (40). A cross-sectional study among 254 university students in Shiraz also showed no association between VDD and sun exposure(41). Moreover, there was no association found between dietary sources of vitamin D and VDD. One reason could be the low consumption of fish and milk and vitamin $\mathrm{D}$ fortified food items in our population.

Our study has several strengths. The study collected comprehensive information on all potential factors associated with VDD. The data was collected by trained medical officers with expertise in both medical history taking and research. The main weakness of the study is the recall bias which is inherent in any cross sectional or case control study. Awareness programs and education about the importance of adequate vitamin $D$ levels, are needed for sensible sunlight exposure and adequate nutritional intake of vitamin D-rich foods to prevent adverse health outcomes related to vitamin D deficiency. Supplement use of Vitamin $D$ is particularly important especially during the current pandemic of Covid 19.

\section{Abbreviations}

Cl: Confidence Interval, VDD: Vitamin D deficiency, OR: Odds Ratio; AKU: Aga Khan University.

\section{Declarations}

\section{Acknowledgements None.}

Funding This work was supported by the Deans fund Aga Khan University Hospital grant (201710550 2025150081001 0000). The funding bodies were not involved in the design of this study or in the collection of data, analysis, and interpretation of results.

Availability of data and materials The datasets used and analyzed during the current study are available from the corresponding author on request.

\section{Ethics approval and consent to participate}

The study was performed in accordance with the ethical standards of the Declaration of Helsinki (1964) and its subsequent amendments. The ethical approval was obtained by the Human Research Ethics Committee of the University of Adelaide, Australia (H-2014-111) and the Ethical Review Committees of Aga Khan University Hospital, Karachi Pakistan (3074-CHS-ERC-14). Informed consent was obtained using the Patient Information Sheet and Consent form. Participants were clearly informed about the 
objectives and procedures of the study, their rights and commitments, and the benefits and risks involved. If the patients agreed to participate, they were asked to sign the consent paper. The consent form of the study was provided both in English and the local language of Urdu. If unable to read the consent form, the form was read out to participants and informed consent was taken verbally.

Consent for publication Not applicable.

Competing interests The authors declare that they have no conflict of interest.

Authors' contributions US participated in the design of the study, acquisition of data, performed the statistical analysis, and drafted the manuscript. DC made substantial contributions to conception and design, interpretation of data, acquisition of data, and interpretation of data. IA performed the statistical analysis and contributed to interpretation of data. AS \& DS made contribution to manuscript writing and proofreading it. All authors were involved in revising the manuscript critically for important intellectual content, and final approval of the version to be published.

\section{Author details}

${ }^{1}$ Adelaide Medical School, University of Adelaide, Australia,

${ }^{2}$ Department of Community Health Sciences, Aga Khan University, Karachi, Pakistan

${ }^{3}$ Department of Gynecology \& Obstetrics, Combined Military Hospital, Karachi, Pakistan

${ }^{4}$ Division of Data Science, University of California, Berkeley, United States

\section{References}

1. Mariani J, Gimenez VMM, Bergam I, Tajer C, Antonietti L, Inserra F, et al. Association Between Vitamin D Deficiency and COVID-19 Incidence, Complications, and Mortality in 46 Countries: An Ecological Study. Health Secur. 2020.

2. Meltzer DO, Best TJ, Zhang H, Vokes T, Arora V, Solway J. Association of Vitamin D Status and Other Clinical Characteristics With COVID-19 Test Results. JAMA Netw Open. 2020;3(9):e2019722.

3. Kandhro F, Dahot U, Naqvi SHA, Ujjan IU. Study of Vitamin D deficiency and contributing factors in the population of Hyderabad, Pakistan. Pak J Pharm Sci. 2019;32(3):1063-8.

4. Jadoon SA, Ahmed A, Alam MA. Vitamin D Deficiency In Pakistan: Tip Of Iceberg. J Ayub Med Coll Abbottabad. 2018;30(1):78-80.

5. Sheikh A, Saeed Z, Jafri SA, Yazdani I, Hussain SA. Vitamin D levels in asymptomatic adults-a population survey in Karachi, Pakistan. PLoS One. 2012;7(3):e33452.

6. Khan AH, lqbal R, Naureen G, Dar FJ, Ahmed FN. Prevalence of vitamin D deficiency and its correlates: results of a community-based study conducted in Karachi, Pakistan. Arch Osteoporos. 2012;7:275-82. 
7. Nadeem S, Munim TF, Hussain HF, Hussain DF. Determinants of Vitamin D deficiency in asymptomatic healthy young medical students. Pak J Med Sci. 2018;34(5):1248-52.

8. Shamsi U, Khan S, Azam I, Habib Khan A, Maqbool A, Hanif M, et al. A multicenter case control study of association of vitamin D with breast cancer among women in Karachi, Pakistan. PLoS One. 2020;15(1):e0225402.

9. Humayun Q, Iqbal R, Azam I, Khan AH, Siddiqui AR, Baig-Ansari N. Development and validation of sunlight exposure measurement questionnaire (SEM-Q) for use in adult population residing in Pakistan. BMC Public Health. 2012;12:421.

10. Holick MF. Vitamin D deficiency. N Engl J Med. 2007;357(3):266-81.

11. Obesity: preventing and managing the global epidemic. Report of a WHO consultation. World Health Organ Tech Rep Ser. 2000;894:i-xii, 1-253.

12. Kiani IG, Shah F, Mansur SS. Frequency of severe vitamin-D deficiency in patients presenting to a tertiary care hospital in Islamabad. J Pak Med Assoc. 2014;64(10):1138-40.

13. Levis S, Gomez A, Jimenez C, Veras L, Ma F, Lai S, et al. Vitamin d deficiency and seasonal variation in an adult South Florida population. J Clin Endocrinol Metab. 2005;90(3):1557-62.

14. Junaid K, Rehman A, Jolliffe DA, Wood K, Martineau AR. High prevalence of vitamin D deficiency among women of child-bearing age in Lahore Pakistan, associating with lack of sun exposure and illiteracy. BMC Womens Health. 2015;15:83.

15. Gordon CM, DePeter KC, Feldman HA, Grace E, Emans SJ. Prevalence of vitamin D deficiency among healthy adolescents. Arch Pediatr Adolesc Med. 2004;158(6):531-7.

16. Furuya T, Hosoi T, Tanaka E, Nakajima A, Taniguchi A, Momohara S, et al. Prevalence of and factors associated with vitamin $D$ deficiency in 4,793 Japanese patients with rheumatoid arthritis. Clin Rheumatol. 2013;32(7):1081-7.

17. Vandevijvere S, Amsalkhir S, Van Oyen H, Moreno-Reyes R. High prevalence of vitamin D deficiency in pregnant women: a national cross-sectional survey. PLoS One. 2012;7(8):e43868.

18. Richard A, Rohrmann S, Quack Lotscher KC. Prevalence of Vitamin D Deficiency and Its Associations with Skin Color in Pregnant Women in the First Trimester in a Sample from Switzerland. Nutrients. 2017;9(3).

19. Fang F, Wei H, Wang K, Tan L, Zhang W, Ding L, et al. High prevalence of vitamin D deficiency and influencing factors among urban and rural residents in Tianjin, China. Arch Osteoporos. 2018;13(1):64.

20. Lopes VM, Lopes JR, Brasileiro JP, Oliveira I, Lacerda RP, Andrade MR, et al. Highly prevalence of vitamin D deficiency among Brazilian women of reproductive age. Arch Endocrinol Metab. 2017;61(1):21-7.

21. Mehboobali N, Iqbal SP, lqbal MP. High prevalence of vitamin D deficiency and insufficiency in a low income peri-urban community in Karachi. J Pak Med Assoc. 2015;65(9):946-49. 
22. Kaptein EM, Yi SS, Endres DB, Kaptein JS, Chan LS. Vitamin D deficiency in urban indigent patients in Southern California. Endocr Pract. 2013;19(3):404-13.

23. Horton-French K, Dunlop E, Lucas RM, Pereira G, Black LJ. Prevalence and Predictors of Vitamin D Deficiency among African Immigrants Living in Australia. Int J Environ Res Public Health. 2019;16(16).

24. Malacova E, Cheang PR, Dunlop E, Sherriff JL, Lucas RM, Daly RM, et al. Prevalence and predictors of vitamin D deficiency in a nationally representative sample of adults participating in the 20112013 Australian Health Survey. Br J Nutr. 2019;121(8):894-904.

25. Al Zarooni AAR, Al Marzouqi FI, Al Darmaki SH, Prinsloo EAM, Nagelkerke N. Prevalence of vitamin D deficiency and associated comorbidities among Abu Dhabi Emirates population. BMC Res Notes. 2019;12(1):503.

26. Kanatani KT, Nakayama T, Adachi Y, Hamazaki K, Onishi K, Konishi Y, et al. High frequency of vitamin $D$ deficiency in current pregnant Japanese women associated with UV avoidance and hypo-vitamin D diet. PLoS One. 2019;14(3):e0213264.

27. Raza A, Syed JG, Muhammad Ali F, Danish Khan M, Ali Khan M, Haleem F, et al. Incidence of Vitamin D Deficiency in Different Seasons in the Adult Karachi Population Presenting in the Medical Outpatient Department with Generalized Body Ache. Cureus. 2019;11(7):e5167.

28. Jiang W, Wu DB, Xiao GB, Ding B, Chen EQ. An epidemiology survey of vitamin D deficiency and its influencing factors. Med Clin (Barc). 2020;154(1):7-12.

29. Woon FC, Chin YS, Ismail IH, Batterham M, Abdul Latiff AH, Gan WY, et al. Vitamin D deficiency during pregnancy and its associated factors among third trimester Malaysian pregnant women. PLoS One. 2019;14(6):e0216439.

30. AlFaris NA, AlKehayez NM, AlMushawah FI, AINaeem AN, AlAmri ND, AlMudawah ES. Vitamin D Deficiency and Associated Risk Factors in Women from Riyadh, Saudi Arabia. Sci Rep. 2019;9(1):20371.

31. AIQuaiz AM, Kazi A, Fouda M, Alyousefi N. Age and gender differences in the prevalence and correlates of vitamin D deficiency. Arch Osteoporos. 2018;13(1):49.

32. Deplanque $X$, Wullens A, Norberciak L. [Prevalence and risk factors of vitamin D deficiency in healthy adults aged 18-65 years in northern France]. Rev Med Interne. 2017;38(6):368-73.

33. Mitchell DM, Henao MP, Finkelstein JS, Burnett-Bowie SA. Prevalence and predictors of vitamin D deficiency in healthy adults. Endocr Pract. 2012;18(6):914-23.

34. Liu X, Baylin A, Levy PD. Vitamin D deficiency and insufficiency among US adults: prevalence, predictors and clinical implications. Br J Nutr. 2018;119(8):928-36.

35. Alloubani A, Akhu-Zaheya L, Samara R, Abdulhafiz I, Saleh A, Altowijri A. Relationship between Vitamin D Deficiency, Diabetes, and Obesity. Diabetes Metab Syndr. 2019;13(2):1457-61.

36. Krieger JP, Cabaset S, Canonica C, Christoffel L, Richard A, Schroder T, et al. Prevalence and determinants of vitamin $D$ deficiency in the third trimester of pregnancy: a multicentre study in Switzerland. Br J Nutr. 2018;119(3):299-309. 
37. Ning Z, Song S, Miao L, Zhang P, Wang X, Liu J, et al. High prevalence of vitamin D deficiency in urban health checkup population. Clin Nutr. 2016;35(4):859-63.

38. Quaggiotto $P$, Tran $H$, Bhanugopan M. Vitamin D deficiency remains prevalent despite increased laboratory testing in New South Wales, Australia. Singapore Med J. 2014;55(5):271-80.

39. Kim SH, Oh MK, Namgung R, Park MJ. Prevalence of 25-hydroxyvitamin D deficiency in Korean adolescents: association with age, season and parental vitamin D status. Public Health Nutr. 2014;17(1):122-30.

40. Bittar FB, Castro CHM, Szejnfeld VL. Screening for vitamin D deficiency in a tropical area: results of a sun exposure questionnaire. BMC Endocr Disord. 2018;18(1):44.

41. Faghih S, Abdolahzadeh M, Mohammadi M, Hasanzadeh J. Prevalence of vitamin d deficiency and its related factors among university students in shiraz, iran. Int J Prev Med. 2014;5(6):796-9.

\section{Supplementary Files}

This is a list of supplementary files associated with this preprint. Click to download.

- TableA.Scoringforestimationofsunlightexposure.docx 